\title{
Serum homocysteine levels are correlated with behavioral and psychological symptoms of Alzheimer's disease
}

This article was published in the following Dove Press journal:

Neuropsychiatric Disease and Treatment

3 October 2014

Number of times this article has been viewed

\author{
Hyun Kim \\ Kang Joon Lee \\ Department of Psychiatry, Ilsan Paik \\ Hospital, Inje University College \\ of Medicine, Goyang, South Korea
}

Correspondence: Kang Joon Lee Department of Psychiatry, Ilsan Paik Hospital, Inje University College of Medicine, 170, Juhwa-ro, Ilsanseo-gu, Goyang-si, Gyeonggi-do 4II-706,

South Korea

Tel +82319107260

Fax +82319107268

Email lkj@paik.ac.kr
Purpose: Homocysteine has been associated with cognitive impairment and various psychiatric symptoms. This study was designed to clarify whether a relationship exists between the serum levels of homocysteine and the behavioral and psychological symptoms of dementia.

Methods: Patients with Alzheimer's disease $(n=77)$ and control subjects $(n=37)$ were included in this study. History taking, physical examination, and cognitive assessment were carried out as part of the investigation for the diagnosis of Alzheimer's disease based on the Diagnostic and Statistical Manual of Mental Disorders, Fourth Edition. The Mini-Mental State Examination, Global Deterioration Scale, Clinical Dementia Rating, and the Korean version of the Neuropsychiatric Inventory were applied to all patients. The patients' serum homocysteine, folate, and vitamin $\mathrm{B}_{12}$ levels were measured.

Results: Patients with Alzheimer's disease had statistically significantly lower Mini-Mental State Examination scores and higher serum homocysteine levels compared to the control subjects. Mean serum folate and vitamin $B_{12}$ concentration were significantly lower in patients with Alzheimer's disease compared to control subjects. A statistically significant positive correlation was found between the serum homocysteine levels and the Neuropsychiatric Inventory subdomains, including delusion, agitation/aggression, depression/dysphoria, elation/euphoria, apathy/ indifference, and disinhibition. No statistically significant correlation was found between the serum homocysteine concentration and the Mini-Mental State Examination, Global Deterioration Scale, or Clinical Dementia Rating.

Conclusion: Associations between the serum homocysteine levels and behavioral and psychological symptoms of dementia were observed, raising the possibility of an etiological role. However, the correlations between the folate or vitamin $B_{12}$ levels and the Neuropsychiatric Inventory scores were not significant. The pathophysiological mechanisms underlying these findings remain to be elucidated. This was a cross-sectional study and the findings should be confirmed by repetitive, prospective longitudinal studies in a larger group of patients with neurodegenerative disorders.

Keywords: Alzheimer's disease, homocysteine, behavioral and psychological symptoms of dementia (BPSD)

\section{Introduction}

Alzheimer's disease (AD), which is the most common form of dementia, causes a gradual degeneration of the cognitive functions, overall damage to the intellectual functions, and behavioral disorders and psychological symptoms. Because of the difficulties in treatment, emphasis is placed on the importance of prevention, early detection, and early treatment. Elderly patients with AD show a decreased ability to manage the activities of independent daily life and require nursing, thus increasing the burden on families and society. 
Among the tests which may help in the diagnosis of $\mathrm{AD}$, blood tests for the levels of homocysteine, folate, or vitamin $B_{12}$ are often used. Since a close correlation between increased homocysteine levels and $\mathrm{AD}$ has been revealed, measurement of the homocysteine concentration is currently considered a necessary component of the AD diagnostic process. ${ }^{1}$ In addition, as some reports have shown that the vitamin $\mathrm{B}_{12}$ and folate levels may not reflect the current disease status, the homocysteine levels are considered a better test than measurements of vitamin $\mathrm{B}_{12}$ and folate. ${ }^{2}$ Homocysteine is produced during the metabolism of methionine, which is an essential amino acid. When homocysteine is not converted to cysteine or methionine but accumulated inordinately, this causes cardiovascular disease. Accumulated homocysteine inhibits the production of prostacyclin, which is a factor that controls the blood pressure and thrombus formation, and leads to the accumulation of low-density lipoprotein, resulting in damage to the blood vessel walls. Eventually, homocysteine damages the blood vessels and causes thrombosis or blood clotting, making it one of the strongest toxic substances in the body and one which leads to cardiovascular and cerebrovascular disorders such as arteriosclerosis, dementia, and stroke. ${ }^{3,4}$ Since the enzymes necessary to degrade homocysteine or to convert it to cysteine or methionine require folate and vitamin $\mathrm{B}_{12}$, a lack of folate and vitamin $B_{12}$ results in increased blood homocysteine levels. ${ }^{1}$

Recent studies have shown that homocysteine levels are a sensitive marker of folate and vitamin $\mathrm{B}_{12}$ levels and that increased blood homocysteine levels are correlated not only with cardiovascular disease but also with the severity of cognitive damage and dementia. In addition, it has been reported that hyperhomocysteinemia is correlated with psychosis, depression, and other psychiatric disorders. ${ }^{5,6}$ Using the plasma homocysteine levels as a modality to determine the presence of a functional folate deficiency, ${ }^{7}$ a recent report identified a biological subgroup of depression with folate deficiency, impaired methylation, and monoamine neurotransmitter metabolism. Elevated levels of homocysteine in young male patients with schizophrenia have also been reported to be potentially related to the pathophysiology of psychotic disorders. ${ }^{8}$ From that point of view, it is presumed that the behavioral and psychological symptoms of dementia (BPSD) may be correlated with homocysteine. Furthermore, a correlation may be assumed not only with $\mathrm{AD}$ but also with other types of dementia, such as frontotemporal dementia, in which behavioral abnormalities are observed.

Studies on the correlation between serum homocysteine levels and BPSD are very sparse. The existing research has produced conflicting results and has only focused on $\mathrm{AD}$ and vitamin $\mathrm{B}_{12}{ }^{9}{ }^{9} 10 \mathrm{In}$ this study, on the basis of various results suggesting that homocysteine levels are correlated with the risk and symptoms of $\mathrm{AD}$, the serum homocysteine levels in Korean $\mathrm{AD}$ patients were measured and it was investigated whether a correlation existed between increased serum homocysteine levels and the extent of BPSD. No previous research had been conducted on the correlation between BPSD and serum homocysteine levels in Koreans. This study was conducted in order to overcome the methodological shortcomings of formerly published studies such as poorly defined patient populations and extensive behavioral observations. The results of this study may help with the clinical diagnosis and treatment of dementia in the future.

\section{Methods}

\section{Subjects and methods}

A total of 77 patients who visited the dementia clinic of the Department of Psychiatry at Ilsan Paik Hospital (Goyang, South Korea) from September 2011 to January 2014 were included in this study. History taking, mental status examination, physical examination, neurocognitive function testing, and blood tests were carried out as part of the investigation for the diagnosis of $\mathrm{AD}$. The study population was composed of patients who had scored 23 or lower on the Korean version of the Mini-Mental State Examination (MMSE) included in the Consortium to Establish a Registry for AD Assessment Packet (MMSE-KC) and whose age was 65 years or higher among those who were diagnosed with $\mathrm{AD}$ according to the Diagnostic and Statistical Manual of Mental Disorders, Fourth Edition (DSM-IV) diagnostic criteria. Patients who had taken acetylcholinesterase inhibitors, antipsychotic drugs, benzodiazepines, and antidepressants were excluded. Patients with pharmacologically well-compensated vascular risk factors - such as diabetes, hypertension, or dyslipidemia - were enrolled. In this study, the healthy control group (24 females and 13 males) included communitydwelling, age-matched subjects with no sign of cognitive impairment (MMSE score of $>26$ ). Subjects who had been diagnosed with types of dementia other than $\mathrm{AD}$, those with a history of head or brain injury, drug abuse, neoplastic or hematologic disorders, myocardial infarction, recent infections or surgery, severe hepatic or renal insufficiency, and anti-inflammatory, corticosteroid, or immunosuppressive treatments, as well as those with degenerative disorders of the nervous system (eg, Parkinson's disease or Huntington's disease), those with thyroid function abnormalities or other physical illnesses which might affect cognitive functions, 
and those with accompanying psychotic disorders or mood disorders were excluded. In addition, patients who had received oral administration of folate or vitamin $B_{12}$ were also excluded. The patients' overall cognitive function and disease severity was measured using the MMSE-KC, ${ }^{11}$ the Global Deterioration Scale (GDS), ${ }^{12}$ and the Clinical Dementia Rating (CDR). ${ }^{13}$ The existence and patterns of behavioral disorders and psychiatric symptoms in the patients were evaluated with the Korean version of the Neuropsychiatric Inventory (K-NPI). The study was carried out on every new patient who visited the hospital, who had taken every test required, which might lengthen the registration period. This study was reviewed and approved by the Institutional Review Board of Ilsan Paik Hospital at Inje University.

\section{Assessment tools MMSE-KC}

The English version of the MMSE included in the Consortium to Establish a Registry for AD Assessment Packet was adapted by partially modifying the MMSE developed by Folstein et $\mathrm{al}^{14}$ to specifically describe some of the questions and grading standards, although the overall test structure remained nearly the same as in the Folstein et al's MMSE. The MMSE-KC was prepared by translating the questions, methods, and grading standards of the MMSE in the Consortium to Establish a Registry for AD Assessment Package and referring to the Korean version of the MMSE, ${ }^{15}$ which has been extensively used in Korea, with respect to some of the questions. In this study, a score of 21-26 on the MMSE scale fell into the mild dementia category, while a score of eleven to 20 indicated moderate dementia.

\section{GDS}

The GDS is an assessment tool measuring not only the cognitive functions but also the activities of daily living and abnormal behaviors of patients, without being significantly affected by their educational level. The GDS classifies the clinical stages of dementia into seven grades, including the predementia stages of grades I-III and the dementia stages of grades IV-VII. The reliability of the GDS has been verified in Korea, and its validity has been proven, by showing excellent correlations with other dementia assessment tools. ${ }^{16}$ Since the GDS can reflect changes in patients over time, the tool may be effectively used to assess prognosis or the efficacy of dementia treatment.

\section{CDR}

The CDR is an assessment tool used to rate the cognitive and social functions of a patient through an interview with the patient and a caregiver of the patient. The CDR includes six detailed items - memory, orientation, judgment and problem-solving, community affairs, home and hobbies, and personal care - each of which is rated between zero and three.

\section{$\mathrm{K}-\mathrm{NPI}$}

The NPI was developed to assess the behavioral disorders of dementia patients. It has been verified with respect to its validity and reliability, and has been translated into many languages and used in many countries. ${ }^{17-19}$ In Korea, a standardized K-NPI has been developed and verified many times with respect to its validity and reliability. The NPI examines 12 subdomains of abnormal behavior in dementia patients, namely delusion, hallucination, agitation/ aggression, depression/dysphoria, anxiety, euphoria/elation, apathy/indifference, disinhibition, irritability/lability, aberrant motor behavior, sleep/night-time behavior, and appetite/ eating changes, as well as the amount of caregiver distress caused by each of the behaviors. The patients were rated according to the behavioral changes they displayed for the 12 subdomains in the 4 weeks prior to the assessment. When a specific abnormal behavior was found in one of the subdomains, a composite score (zero to 12 points) was obtained by multiplying the score for frequency (zero to four) with the score for severity (zero to three). The composite scores of the 12 subdomains were then added up to obtain the total K-NPI score (zero to 144).

\section{Blood sampling}

The blood homocysteine, folate, and vitamin $\mathrm{B}_{12}$ concentrations were measured for patients in both groups. The patients' blood samples were taken intravenously from an upper limb in the morning, after a period of fasting of 12 hours or longer. The blood samples were stored in Vacutainer ${ }^{\circledR}$ tubes containing citrate, were cooled with ice, and were immediately centrifuged at 3,000 rpm for 10 minutes. The serum was then kept in a freezer at $-70^{\circ} \mathrm{C}$. The homocysteine levels in the serum samples were measured through fluorescence polarization immunoassay.

\section{Statistics}

The data were analyzed using SPSS 15.0 for Windows ${ }^{\circledR}$. A probability level of $P<0.05$ was considered significant. An independent Student's $t$-test was performed to analyze the statistical information by dividing the patients into two groups according to the MMSE scores. A chi-square test was performed to analyze the categorical variables. The correlations 
of the homocysteine, folate, and vitamin $\mathrm{B}_{12}$ concentrations with the MMSE-KC, GDS, CDR, and NPI scores were analyzed using Pearson's correlation test.

\section{Results}

\section{Demographic and clinical data}

The baseline characteristics of the control group and AD group enrolled in the study are reported in Table 1 . No differences in age and sex were found between the two groups. The patients with AD had statistically significantly lower MMSE scores and higher GDS and CDR scores compared with the control group $(P<0.01)$. There were no significant differences in the levels of blood urea nitrogen and creatinine between the two groups.

Table 3 shows the mean NPI scores for each subdomain. The NPI scores of the moderate dementia patients were higher in general than those of the mild dementia patients, indicating a tendency for behavioral symptoms to increase as $\mathrm{AD}$ progresses.

\section{Homocysteine, folate, and vitamin $B_{12}$ concentrations in the subjects}

In the control group, the mean homocysteine, folate, and vitamin $\mathrm{B}_{12}$ concentrations were $9.84 \pm 3.06 \mu \mathrm{mol} / \mathrm{L}, 13.41 \pm 7.56 \mathrm{ng} / \mathrm{mL}$, and $677.86 \pm 233.61 \mathrm{pg} / \mathrm{mL}$, respectively. As shown in Table 1, the patients with $\mathrm{AD}$ had significantly higher serum homocysteine levels compared to the control subjects $(P<0.01)$. The mean serum folate concentrations were significantly lower in patients with AD compared to the control subjects $(P<0.01)$. The normal range of folate was $3.1-17.5 \mathrm{ng} / \mathrm{mL}$, and the concentration of the control group and patient group in this study was generally low.
The total number of AD patients in this study was 77, including 26 male patients and 51 female patients. The number of mild dementia patients (MMSE score of 21-26) was 26, while the number of moderate dementia patients (MMSE score of eleven to 20) was 51 (Table 2). In the entire group of patients, the mean serum homocysteine level was 13.35 $\pm 5.72 \mu \mathrm{mol} / \mathrm{L}$, and the folate and vitamin $\mathrm{B}_{12}$ concentrations were $10.26 \pm 6.8 \mathrm{ng} / \mathrm{mL}$ and $578.98 \pm 235.93 \mathrm{pg} / \mathrm{mL}$, respectively. In the mild dementia patient group (MMSE score of $\geq 21$ ) the mean homocysteine, folate, and vitamin $B_{12}$ concentrations were $12.71 \pm 4.43 \mu \mathrm{mol} / \mathrm{L}, 13.63 \pm 9.07 \mathrm{ng} / \mathrm{mL}$, and $644.29 \pm 259.73 \mathrm{pg} / \mathrm{mL}$, respectively. In the moderate dementia patient group (MMSE score $<21$ ), the mean homocysteine, folate, and vitamin $\mathrm{B}_{12}$ concentrations were $13.68 \pm 6.29 \mu \mathrm{mol} / \mathrm{L}, 8.55 \pm 4.5 \mathrm{ng} / \mathrm{mL}$, and $545.11 \pm 220 \mathrm{pg} / \mathrm{mL}$, respectively. The homocysteine and vitamin $\mathrm{B}_{12}$ concentrations did not differ significantly between the two groups, but the folate was significantly lower in the moderate dementia patient group (Table 2).

\section{Correlation of homocysteine, folate, and vitamin $B_{12}$ concentrations with NPI subdomains, MMSE-KC, GDS, and CDR}

The results of the Pearson's correlation test showed a significant correlation between the serum homocysteine levels and the total NPI score. With respect to each NPI subdomain, a significant correlation was found with delusion, agitation/aggression, depression/dysphoria, elation/ euphoria, apathy/indifference, and disinhibition (Table 4). However, no significant correlation was found with the other six NPI subdomains. A significant correlation was found with disinhibition in the mild dementia patient group,

Table I Demographic and clinical data of patients with Alzheimer's disease and controls

\begin{tabular}{|c|c|c|c|c|}
\hline & \multirow{2}{*}{$\begin{array}{l}\text { Controls } \\
(\mathbf{N}=37)\end{array}$} & \multirow{2}{*}{$\begin{array}{l}\text { AD } \\
(N=77)\end{array}$} & \multicolumn{2}{|c|}{ Controls versus AD } \\
\hline & & & Statistics value & $P$-value \\
\hline Sex (female) & $13(24)$ & $26(5 I)$ & 0.021 & 0.885 \\
\hline Age & $75.86(5.74)$ & $76.73(7.63)$ & 0.609 & 0.544 \\
\hline Homocysteine $(\mu \mathrm{mol} / \mathrm{L})$ & $9.84(3.06)$ & $13.35(5.72)$ & 3.489 & $0.00 I^{* *}$ \\
\hline Folate $(\mathrm{ng} / \mathrm{mL})$ & $13.4 \mid(7.56)$ & $10.26(6.8)$ & -2.88 & $0.005^{* *}$ \\
\hline Vitamin $B_{12}(p g / m L)$ & $677.86(233.6 I)$ & $578.98(235.93)$ & 1.363 & 0.176 \\
\hline Blood urea nitrogen (mg/dL) & $16.06(4.52)$ & $19.33(11.47)$ & 1.522 & 0.132 \\
\hline Creatinine $(\mathrm{mg} / \mathrm{dL})$ & $0.9(0.25)$ & $1.04(0.57)$ & 1.335 & 0.185 \\
\hline MMSE & $27.03(1.36)$ & $17.35(5.19)$ & -10.997 & $0.000 * *$ \\
\hline GDS & $\mathrm{I} .8 \mathrm{I}(0.75)$ & $4.2(0.95)$ & $13.24 \mid$ & $0.000 * *$ \\
\hline CDR & $0.14(0.23)$ & $1.00(0.38)$ & 12.474 & $0.000 * *$ \\
\hline NPI total & $2.56(2.5 \mathrm{I})$ & $15.08(18.34)$ & 2.036 & $0.045^{*}$ \\
\hline
\end{tabular}

Notes: Values represent mean (standard deviation). *Significant at $P<0.05$. **Significant at $P<0.01$.

Abbreviations: AD, Alzheimer's disease; CDR, Clinical Dementia Rating Scale; GDS, Global Deterioration Scale; MMSE, Mini Mental State Examination; NPI, Neuropsychiatric Inventory. 
Table 2 Demographic and clinical data of patients with Alzheimer's disease

\begin{tabular}{|c|c|c|c|c|c|}
\hline & \multirow{2}{*}{$\begin{array}{l}\text { Total AD } \\
(\mathbf{N}=77)\end{array}$} & \multirow{2}{*}{$\begin{array}{l}\text { Mild AD } \\
(\mathbf{N}=26)\end{array}$} & \multirow{2}{*}{$\begin{array}{l}\text { Moderate AD } \\
(\mathrm{N}=5 \mathrm{I})\end{array}$} & \multicolumn{2}{|c|}{ Mild versus moderate AD } \\
\hline & & & & Statistics value & $P$-value \\
\hline Sex (female) & $26(5 I)$ & $10(16)$ & $16(35)$ & 0.387 & 0.613 \\
\hline Age & $76.73(7.63)$ & $77.23(6.77)$ & $76.47(8.08)$ & $0.4 \mathrm{II}$ & 0.341 \\
\hline Homocysteine $(\mu \mathrm{mol} / \mathrm{L})$ & $13.35(5.72)$ & I2.7| (4.43) & $13.68(6.29)$ & -0.698 & 0.243 \\
\hline Folate $(\mathrm{ng} / \mathrm{mL})$ & $10.27(6.8)$ & $13.63(9.07)$ & $8.55(4.5)$ & 3.291 & $0.00 I^{* *}$ \\
\hline Vitamin $B_{12}(p g / m L)$ & $578.98(235.93)$ & $644.29(259.73)$ & $545.11(220)$ & 0.883 & 0.353 \\
\hline MMSE & $17.35(5.19)$ & $22.54(1.88)$ & I 4.7 (4.23) & 8.96 & $0.000^{* *}$ \\
\hline GDS & $4.2(0.95)$ & $3.77(0.65)$ & $4.42(1.01)$ & -2.97 & $0.02 *$ \\
\hline CDR & $1.00(0.38)$ & $0.79(0.25)$ & I.II (0.39) & -3.77 & $0.000 * *$ \\
\hline NPI total & I5.08 (18.34) & $10.46(12.32)$ & $17.48(20.5)$ & -1.6 & 0.057 \\
\hline
\end{tabular}

Notes: Data represents mean (standard deviation). *Significant at $P<0.05$. **Significant at $P<0.01$.

Abbreviations: AD, Alzheimer's disease; CDR, Clinical Dementia Rating Scale; GDS, Global Deterioration Scale; MMSE, Mini Mental State Examination; NPI, Neuropsychiatric Inventory.

whereas a significant correlation was found with delusion and depression/dysphoria in moderate patients.

The correlations of the serum homocysteine level and the MMSE-KC, GDS, and CDR scores in patients with AD were not significant. The correlations between the folate or vitamin $\mathrm{B}_{12}$ concentration and the NPI, MMSE-KC, GDS, and CDR scores were also not significant (Table 5).

\section{Discussion}

This study was conducted to investigate the correlations of homocysteine, folate, and vitamin $\mathrm{B}_{12}$ concentrations with BPSD in patients with AD. Although the correlations of homocysteine, folate, and vitamin $\mathrm{B}_{12}$ concentrations with cognitive functions have been previously investigated in a number of studies, there had been very little focus to date on the correlations with BPSD. The results of this study showed that there was a significant correlation between the serum homocysteine levels and the total NPI score of AD patients. In particular, a significant correlation was found with the following NPI subdomains: delusion, agitation/aggression, depression/dysphoria, elation/euphoria, apathy/indifference, and disinhibition. BPSD in the moderate dementia patient group was found to be more closely correlated with the concentration of homocysteine than in the mild dementia patient group. This highlights that the correlation between homocysteine and behavioral symptoms increases as $\mathrm{AD}$ progresses. These results contrast with the findings of Tabet et al's previous study, which found that homocysteine levels are not significantly correlated with BPSD, ${ }^{20}$ but are in accordance with other studies indicating that homocysteine levels are significantly correlated with BPSD..$^{5,6,21-23}$ In addition, the results of this study showed that folate and vitamin $\mathrm{B}_{12}$ concentrations are not correlated with BPSD, which is similar to the results of Engelborghs et al ${ }^{8}$ and Whyte et al. ${ }^{10}$

Table 3 Mean Neuropsychiatric Inventory scores of patients with Alzheimer's disease

\begin{tabular}{|c|c|c|c|c|c|}
\hline & \multirow{2}{*}{$\begin{array}{l}\text { Mean NPI } \\
\text { score of total } \\
\text { AD }(\mathbf{N}=77)\end{array}$} & \multirow{2}{*}{$\begin{array}{l}\text { Mean NPI } \\
\text { score of mild } \\
\text { AD }(\mathbf{N}=26)\end{array}$} & \multirow{2}{*}{$\begin{array}{l}\text { Mean NPI score } \\
\text { of moderate } \\
\text { AD }(\mathbf{N}=5 \mathrm{I})\end{array}$} & \multicolumn{2}{|c|}{ Mild versus moderate $A D$} \\
\hline & & & & Statistics value & $P$-value \\
\hline Delusion & $1.53(2.92)$ & $\mathrm{I} .08(2.6)$ & $1.76(3.07)$ & -0.967 & 0.336 \\
\hline Hallucination & $0.83(2.47)$ & $0.5(2.35)$ & $1.00(2.54)$ & -0.834 & 0.407 \\
\hline Agitation/aggression & $1.59(2.65)$ & $0.96(2.39)$ & $1.92(2.74)$ & -1.509 & 0.136 \\
\hline Depression/dysphoria & $\mathrm{I} .42(2.38)$ & $1.12(1.31)$ & $1.59(2.78)$ & -0.806 & 0.423 \\
\hline Anxiety & $\mathrm{I} .28(2.1)$ & $0.62(0.94)$ & $1.62(2.49)$ & -2.011 & $0.048^{*}$ \\
\hline Euphoria/elation & $0.21(0.80)$ & $0.08(0.39)$ & $0.28(0.95)$ & -1.044 & 0.300 \\
\hline Apathy/indifference & $2.13(3.21)$ & $1.38(2.19)$ & 2.52 (3.59) & -1.472 & 0.145 \\
\hline Disinhibition & $0.66(1.9)$ & $0.85(2.48)$ & $0.56(1.54)$ & 0.620 & 0.537 \\
\hline Irritability/lability & $\mathrm{I} .43(2.54)$ & $1.35(2.06)$ & $1.48(2.77)$ & -0.217 & 0.829 \\
\hline Aberrant motor behavior & $1.62(3.48)$ & $0.92(2.6 I)$ & $1.98(3.83)$ & -1.263 & 0.211 \\
\hline Sleep/night time behavior & $1.47(3.00)$ & $0.92(2.5)$ & $1.76(3.21)$ & -1.158 & 0.251 \\
\hline Appetite/eating change & $0.95(1.90)$ & $0.81(1.58)$ & $1.02(2.07)$ & -0.459 & 0.648 \\
\hline
\end{tabular}

Notes: Data represents mean (standard deviation). *Significant at $P<0.05$.

Abbreviations: AD, Alzheimer's disease; NPI, Neuropsychiatric Inventory. 
Table 4 Correlations of serum homocysteine levels and scores of the Neuropsychiatric Inventory

\begin{tabular}{|c|c|c|c|c|c|c|}
\hline & \multicolumn{2}{|c|}{ Total AD } & \multicolumn{2}{|c|}{ Mild AD } & \multicolumn{2}{|c|}{ Moderate AD } \\
\hline & $r$ & $P$-value & $r$ & $P$-value & $r$ & $P$-value \\
\hline Delusion & 0.403 & $0.000 * *$ & 0.102 & 0.620 & 0.489 & $0.000^{* *}$ \\
\hline Hallucination & -0.082 & $0.48 \mathrm{I}$ & -0.051 & 0.803 & -0.104 & 0.472 \\
\hline Agitation/aggression & 0.308 & $0.007^{* *}$ & 0.446 & 0.102 & 0.257 & 0.489 \\
\hline Depression/dysphoria & 0.324 & $0.004 * *$ & 0.057 & 0.780 & 0.366 & $0.009 * *$ \\
\hline Anxiety & -0.020 & 0.867 & 0.044 & 0.830 & -0.051 & 0.725 \\
\hline Euphoria/elation & 0.262 & $0.022 *$ & 0.221 & 0.278 & 0.264 & 0.064 \\
\hline Apathy/indifference & 0.297 & $0.009 * *$ & 0.341 & 0.088 & 0.278 & $0.05 \mathrm{I}$ \\
\hline Disinhibition & 0.261 & $0.023^{*}$ & 0.419 & $0.033^{*}$ & 0.217 & 0.131 \\
\hline Irritability/lability & 0.216 & 0.060 & 0.210 & 0.303 & 0.217 & 0.131 \\
\hline Aberrant motor behavior & 0.142 & 0.221 & -0.032 & 0.875 & 0.172 & 0.231 \\
\hline Sleep/night time behavior & 0.090 & 0.437 & 0.165 & 0.421 & 0.058 & 0.691 \\
\hline Appetite/eating change & 0.206 & 0.074 & 0.126 & $0.54 I$ & 0.224 & 0.118 \\
\hline NPI total & 0.321 & $0.005^{* *}$ & 0.339 & 0.090 & 0.308 & $0.029 *$ \\
\hline
\end{tabular}

Notes: *Significant at $P<0.05$. **Significant at $P<0.01$.

Abbreviations: AD, Alzheimer's disease; NPI, Neuropsychiatric Inventory.

One of the most valuable hypotheses explaining the mechanisms by which homocysteine contributes to $\mathrm{AD}$ pathology is by affecting the cerebrovascular and endothelial compartments, resulting in a chronic perturbation of the neurovascular unit. A direct link between hyperhomocysteinemia and both an increase of endothelial damage and prothrombotic state in $\mathrm{AD}$ has been recently demonstrated by Piazza et al. ${ }^{24}$ Raposo et al also indicate that both compounds, homocysteine and thiolactone, inhibit the activity of lysyl oxidase (an enzyme involved in extracellular matrix maturation) in vascular endothelial cells. ${ }^{25}$ Several lines of evidence suggest that chronic endothelial dysfunction plays a pivotal role in $\mathrm{AD} .{ }^{24}$ Among other mechanisms, it increases oxidative stress and reduces nitric oxide (NO) functioning through the generation of superoxide and the consecutive reaction of this radical with NO to peroxynitrite, a deleterious reactive nitrogen species. ${ }^{26}$ Interestingly, homocysteine impairs the NO pathway by increasing asymmetrical dimethylarginine, ${ }^{27}$ an endogenous NO synthase inhibitor which is also a strong risk factor in cardiovascular disease. Mechanisms such as demethylation, ${ }^{28}$ increased

Table 5 Correlations of serum homocysteine levels and scores of the Mini Mental State Examination, Global Deterioration Scale, and Clinical Dementia Rating Scale

\begin{tabular}{|c|c|c|c|c|c|c|}
\hline & \multicolumn{2}{|c|}{ Total AD } & \multicolumn{2}{|c|}{ Mild AD } & \multicolumn{2}{|c|}{ Moderate AD } \\
\hline & $r$ & $P$-value & $r$ & $P$-value & $r$ & $P$-value \\
\hline MMSE & -0.037 & 0.750 & -0.358 & 0.073 & 0.091 & 0.524 \\
\hline CDR & 0.100 & 0.388 & 0.300 & 0.136 & 0.017 & 0.904 \\
\hline GDS & 0.129 & 0.256 & 0.348 & 0.081 & 0.052 & 0.718 \\
\hline
\end{tabular}

Abbreviations: AD, Alzheimer's disease; CDR, Clinical Dementia Rating Scale; GDS, Global Deterioration Scale; MMSE, Mini Mental State Examination. amyloid-beta, ${ }^{29}$ and phosphorylation of tau proteins ${ }^{30}$ are also involved in the effects of increased serum homocysteine levels on $\mathrm{AD} .{ }^{31}$ However, the detailed mechanisms have not yet been clearly demonstrated.

It has previously been reported that increased homocysteine levels are correlated with decreased cognitive functions. Schafer et al reported that a high homocysteine level was correlated with a decrease in the cognitive functions of elderly people. ${ }^{32}$ The Oxford Project to Investigate Memory and Aging (OPTIMA) also showed that the plasma homocysteine level is negatively correlated with cognitive function scores in elderly populations. ${ }^{33}$ In addition, the Rotterdam Scan Study showed that the cognitive functions decrease as the plasma homocysteine level increases in elderly populations without dementia. ${ }^{34}$ However, Irizarry et al reported that homocysteine levels increase with age, but observed no significant difference in the homocysteine levels between the $\mathrm{AD}$ group and the control group. ${ }^{35}$ Although there are inconsistencies among the previous studies, the overall results show that an increased homocysteine concentration is generally correlated with decreased cognitive functions. However, the results of the current study did not show a significant correlation between the homocysteine concentration and the cognitive functions, which might be because the number of subjects was small.

The correlation between depression and homocysteine in dementia patients has rarely been studied. Chen et al reported that the coexistence of major depressive disorders in patients with moderate AD was correlated with hyperhomocysteinemia. ${ }^{36}$ Several studies have been conducted on the correlation between depression and 
homocysteine in elderly patients, but the results were not consistent. ${ }^{37-40}$ The current study showed a significant correlation between increased homocysteine levels and the NPI score in the depression/dysphoria subdomain, a finding similar to the results of the previous study conducted by Chen et al. ${ }^{36}$ There is no established mechanism regarding the correlation between homocysteine and depression in dementia patients, but several hypotheses have been suggested as to the correlation between homocysteine and depression in elderly patients. One representative theory is the vascular depression hypothesis. It is supported by the comorbidity of depression, vascular disease, and vascular risk factors and the association of ischemic lesions to distinctive behavioral symptoms. The disruption of prefrontal systems or of their modulating pathways by single lesions or by an accumulation of lesions exceeding a threshold is hypothesized as a central mechanism in vascular depression. ${ }^{41}$ According to this hypothesis, it is assumed that hyperhomocysteinemia causes the dysfunction and chronic inflammatory responses of vascular endothelial cells, which exacerbates AD and causes "vascular depression" as a result of the vascular pathology. It has already been shown that the inflammatory response is one of the key mechanisms of AD. ${ }^{42,43}$

This study also showed that there was a significant correlation between homocysteine and elation/euphoria. The correlation between homocysteine and manic symptoms has rarely been studied in dementia patients until now. Focusing on bipolar disorder, disorders in homocysteine metabolism have been observed in patients with bipolar disorder in recent studies. Ozbek et al reported that the homocysteine concentration was higher and the folate concentration was lower in a bipolar disorder patient group than in a normal control group. ${ }^{44}$ As such, it seems that hyperhomocysteinemia plays a certain role in the pathophysiology of neurocognitive deficits in bipolar disorder, ${ }^{45,46}$ but information about the role is lacking. Additional studies will be required to analyze the role of homocysteine in manic symptoms, particularly in the manic symptoms of dementia.

The current study demonstrated that the homocysteine concentration was significantly correlated with the NPI subdomain of apathy/indifference, which is one of the common behavioral symptoms of AD. It has already been reported that a high level of homocysteine is a risk factor for various neuropsychiatric diseases including $\mathrm{AD}^{47}$ and that high homocysteine concentrations are associated with smaller brain volume in the frontal lobe, which has been reported to be associated with apathy. ${ }^{48}$ In addition, it has been suggested that people with $\mathrm{AD}$ who show apathy have some degree of dopaminergic system dysfunction. ${ }^{49}$ High homocysteine levels can cause the dysregulation of one-carbon metabolism, which involves the production of dopamine. Future studies may be required on the correlation between the severity of apathy and the homocysteine concentration depending on sex.

Almost no research has been conducted on the correlation between homocysteine and thought disorders such as delusion. A correlation between homocysteine and schizophrenia has been reported in some studies. Spiro et al reported cases of schizophrenia showing homocystinuria and suggested the possibility of a disorder in the methionine metabolism in some of the schizophrenia cases. ${ }^{50}$ Another study demonstrated that the administration of methionine, which is a precursor of homocysteine, exacerbated the symptoms of schizophrenia patients. ${ }^{51}$ More systematic studies were later conducted, and Regland et al reported, in a study on patients with schizophrenia, that a high homocysteine concentration was found in $45 \%$ of schizophrenia patients. The authors stated that the result was caused by a genetic methylation defect which was unrelated to nutritional status (eg, folate or cobalamin depletion) or to antipsychotic drugs. ${ }^{52}$ Levine et al conducted a study dividing 193 schizophrenia patients and 762 normal control group subjects according to their sex and age, and reported that the blood homocysteine concentration was higher in young male schizophrenia patients. ${ }^{53}$ However, Virgos et al found a contradictory result, reporting that there was no significant difference in the blood homocysteine concentration between schizophrenia patients and normal subjects. ${ }^{54}$ Although the results are not consistent, the previous studies suggest that hyperhomocysteinemia may be correlated to some extent with schizophrenia manifesting a thought disorder. Suggested mechanisms to explain the correlation between hyperhomocysteinemia and schizophrenia are that homocysteine damages the DNA to cause apoptosis and excitotoxicity, and that homocysteine acts as a partial antagonist of the glycine co-agonist site and an agonist at the glutamate site of the N-methyl-D-aspartate receptor. ${ }^{55,56}$ In the current study, the NPI subdomains suggesting psychiatric symptoms such as delusion and agitation/aggression were increased in the AD patients as the homocysteine concentration increased, which allows the assumption that the result in $\mathrm{AD}$ was caused by a mechanism similar to that of schizophrenia. The correlation between homocysteine and disinhibition has never been studied, and thus future studies may be needed in this regard.

This study presents several limitations. First, the number of subjects was not large. Second, the research was conducted 
as a monocentric and retrospective study. Since the study was retrospective, the date of the cognitive function assessment did not coincide with the date of the blood test. Nevertheless, to improve the temporal probability, the interval between the two dates was limited to a 1-month bracket. Furthermore, the collected data regarding the dietary intake of the patients were not sufficient. The serum folate concentration appeared to be low in this study. The authors believe it is important to identify the reason why the folate was low by exploring information.

In summary, associations between homocysteine serum levels and BPSD were observed, raising the possibility of an etiological role. However, as a correlation does not necessarily imply a causative relation, the pathophysiological mechanisms underlying these findings remain to be elucidated. In addition, given the role of vitamin $B_{12}$ and folate in the synthesis of monoamine neurotransmitters ${ }^{37}$ and the existence of neurochemical correlates of BPSD, ${ }^{57}$ it could be hypothesized that a lowered folate and vitamin $B_{12}$ level leading to altered monoaminergic neurotransmission may predispose one to BPSD. However, only correlations between the homocysteine concentration and the NPI scores were found in this study. This was a cross-sectional study and the findings should be confirmed through repetitive, prospective longitudinal studies on a larger group of patients with neurodegenerative disorders. The relationship between low folate, low vitamin $\mathrm{B}_{12}$, or high homocysteine levels and BPSD should also be investigated in more detail. Gaining a greater understanding of the relationships between BPSD and folate, vitamin $\mathrm{B}_{12}$, and homocysteine will determine whether or not the therapeutic trial of folate and vitamin $\mathrm{B}_{12}$ can help BPSD treatment. In addition, the authors believe that related studies about the relationship between BPSD and homocysteine levels in different type of dementia, such as frontotemporal dementia, also need to be explored.

\section{Conclusion}

The serum homocysteine levels in Korean AD patients were measured and it was investigated whether there is a relationship between the serum levels of homocysteine and BPSD. No previous research had been conducted as yet on the correlation between BPSD and serum homocysteine levels in Koreans. The results of this study showed that there was a significant correlation between the homocysteine levels and the total NPI score of AD patients. In particular, a significant correlation was found with the following NPI subdomains: delusion, agitation/aggression, depression/dysphoria, elation/ euphoria, apathy/indifference, and disinhibition. The results of this study may help with the clinical diagnosis and treatment of dementia in the future.

\section{Disclosure}

The authors report no conflicts of interest in this work.

\section{References}

1. Vogel T, Dali-Youcef N, Kaltenbach G, Andres E. Homocysteine, vitamin $\mathrm{B}_{12}$, folate, and cognitive functions: a systematic and critical review of the literature. Int J Clin Pract. 2009;63(7):1061-1067.

2. Nilsson K, Gustafson L, Hultberg B. Plasma homocysteine is a sensitive marker for tissue deficiency of both cobalamines and folates in a psychogeriatric population. Dement Geriatr Cogn Disord. 1999;10(6): 476-482.

3. Facila L, Nunez JE, Bertomeu V, et al. Early determination of homocysteine levels in acute coronary syndromes, is it an independent prognostic factor? Int J Cardiol. 2005;100(2):275-279.

4. Virtanen JK, Voutilainen S, Happonen P, et al. Serum homocysteine, folate, and risk of stroke: Kuopio Ischaemic Heart Disease Risk Factor (KIHD) Study. Eur J Cardiovasc Prev Rehabil. 2005;12(4):369-375.

5. Reif A, Pfuhlmann B, Lesch KP. Homocysteinemia as well as methylenetetrahydrofolate reductase polymorphism are associated with affective psychoses. Prog Neuropsychopharmacol Biol Psychiatry. 2005;29(7):1162-1168.

6. Monji A, Yanagimoto K, Maekawa T, Sumida Y, Yamazaki K, Kojima K. Plasma folate and homocysteine levels may be related to interictal "schizophrenia-like" psychosis in patients with epilepsy. J Clin Psychopharmacol. 2005;25(1):3-5.

7. Stuerenberg HJ, Mueller-Thomsen T, Methner A. Vitamin $B_{12}$ plasma concentrations in Alzheimer disease. Neuro Endocrinol Lett. 2004; 25(3):176-177.

8. Engelborghs S, Vloeberghs E, Maertens K, et al. Correlations between cognitive, behavioural, and psychological findings and levels of vitamin $\mathrm{B}_{12}$ and folate in patients with dementia. Int J Geriatr Psychiatry. 2004; 19(4):365-370.

9. Meins W, Muller-Thomsen T, Meier-Baumgartner HP. Subnormal serum vitamin $\mathrm{B}_{12}$ and behavioural and psychological symptoms in Alzheimer's disease. Int J Geriatr Psychiatry. 2000;15(5):415-418.

10. Whyte EM, Mulsant BH, Butters MA, et al. Cognitive and behavioral correlates of low vitamin $\mathrm{B}_{12}$ levels in elderly patients with progressive dementia. Am J Geriatr Psychiatry. 2002;10(3):321-327.

11. Lee DY, Lee KU, Lee JH, et al. A normative study of the Mini-Mental State Examination in the Korean elderly. Journal of Korean Neuropsychiatric Association. 2002;41(3):508-525.

12. Reisberg B, Ferris SH, de Leon MJ, Crook T. The Global Deterioration Scale for assessment of primary degenerative dementia. Am J Psychiatry. 1982;139(9):1136-1139.

13. Choi SH, Na DL, Lee BH, et al. Estimating the validity of the Korean version of expanded Clinical Dementia Rating (CDR) Scale. Journal of the Korean Neurological Association. 2001;19(6):585-591.

14. Folstein MF, Robins LN, Helzer JE. The Mini-Mental State Examination. Arch Gen Psychiatry. 1983;40(7):812.

15. Park J, Kwon Y. Standardization of Korean version of the Mini-Mental State Examination (MMSE-K) for use in the elderly. Journal of Korean Neuropsychiatric Association. 1989;28:612-617.

16. Choi SH, Na DL, Lee BH, et al. The validity of the Korean version of Global Deterioration Scale. Journal of the Korean Neurological Association. 2002;20(6):612-617.

17. Cummings JL, Mega M, Gray K, Rosenberg-Thompson S, Carusi DA, Gornbein J. The Neuropsychiatric Inventory: comprehensive assessment of psychopathology in dementia. Neurology. 1994;44(12): 2308-2314.

18. Hirono N, Mori E, Ikejiri Y, et al. [Japanese version of the Neuropsychiatric Inventory - a scoring system for neuropsychiatric disturbance in dementia patients]. No To Shinkei. 1997;49(3):266-271. Japanese. 
19. Fuh JL, Liu CK, Mega MS, Wang SJ, Cummings JL. Behavioral disorders and caregivers' reaction in Taiwanese patients with Alzheimer's disease. Int Psychogeriatr. 2001;13(1):121-128.

20. Tabet N, Rafi H, Weaving G, Lyons B, Iversen SA. Behavioural and psychological symptoms of Alzheimer type dementia are not correlated with plasma homocysteine concentration. Dement Geriatr Cogn Disord. 2006;22(5-6):432-438.

21. Chen CS, Tsai JC, Tsang HY, et al. Homocysteine levels, MTHFR C677T genotype, and MRI hyperintensities in late-onset major depressive disorder. Am J Geriatr Psychiatry. 2005;13(10):869-875.

22. Atmaca M, Tezcan E, Kuloglu M, Kirtas O, Ustundag B. Serum folate and homocysteine levels in patients with obsessive-compulsive disorder. Psychiatry Clin Neurosci. 2005;59(5):616-620.

23. Regland B, Abrahamsson L, Blennow K, Grenfeldt B, Gottfries CG CSF-methionine is elevated in psychotic patients. J Neural Transm. 2004;111(5):631-640.

24. Piazza F, Galimberti G, Conti E, et al. Increased tissue factor pathway inhibitor and homocysteine in Alzheimer's disease. Neurobiol Aging 2012;33(2):226-233.

25. Raposo B, Rodriguez C, Martinez-Gonzales J, Badimon L. High levels of homocysteine inhibit lysyl oxidase (LOX) and downregulate LOX expression in vascular endothelial cells. Atherosclerosis. 2004;177(1):1-8.

26. Zhang X, Li H, Jin H, Ebin Z, Brodsky S, Goligorsky MS. Effects of homocysteine on endothelial nitric oxide production. Am J Physiol Renal Physiol. 2000;279(4):F671-F678.

27. Stuhlinger MC, Tsao PS, Her JH, Kimoto M, Balint RF, Cooke JP. Homocysteine impairs the nitric oxide synthase pathway: role of asymmetric dimethylarginine. Circulation. 2001;104(21):2569-2575.

28. Fuso A, Nicolia V, Cavallaro RA, et al. B-vitamin deprivation induces hyperhomocysteinemia and brain S-adenosylhomocysteine, depletes brain S-adenosylmethionine, and enhances PS1 and BACE expression and amyloid-beta deposition in mice. Mol Cell Neurosci. 2008;37(4):731-746.

29. Pacheco-Quinto J, Rodriguez de Turco EB, DeRosa S, et al. Hyperhomocysteinemic Alzheimer's mouse model of amyloidosis shows increased brain amyloid beta peptide levels. Neurobiol Dis. 2006;22(3):651-656.

30. Sontag E, Nunbhakdi-Craig V, Sontag JM, et al. Protein phosphatase 2A methyltransferase links homocysteine metabolism with tau and amyloid precursor protein regulation. J Neurosci. 2007;27(11):2751-2759.

31. Zhuo JM, Wang H, Pratico D. Is hyperhomocysteinemia an Alzheimer's disease (AD) risk factor, an AD marker, or neither? Trends Pharmacol Sci. 2011;32(9):562-571.

32. Schafer JH, Glass TA, Bolla KI, Mintz M, Jedlicka AE, Schwartz BS. Homocysteine and cognitive function in a population-based study of older adults. J Am Geriatr Soc. 2005;53(3):381-388.

33. Budge MM, de Jager C, Hogervorst E, Smith AD. Total plasma homocysteine, age, systolic blood pressure, and cognitive performance in older people. J Am Geriatr Soc. 2002;50(12):2014-2018.

34. Prins ND, Den Heijer T, Hofman A, et al. Homocysteine and cognitive function in the elderly: the Rotterdam Scan Study. Neurology. 2002; 59(9):1375-1380.

35. Irizarry MC, Gurol ME, Raju S, et al. Association of homocysteine with plasma amyloid beta protein in aging and neurodegenerative disease. Neurology. 2005;65(9):1402-1408.

36. Chen CS, Chou MC, Yeh YC, et al. Plasma homocysteine levels and major depressive disorders in Alzheimer disease. Am J Geriatr Psychiatry. 2010;18(11):1045-1048.

37. Bottiglieri T, Laundy M, Crellin R, Toone BK, Carney MW, Reynolds EH. Homocysteine, folate, methylation, and monoamine metabolism in depression. J Neurol Neurosurg Psychiatry. 2000;69(2):228-232.

38. Naismith S, Hickie I, Ward PB, et al. Caudate nucleus volumes and genetic determinants of homocysteine metabolism in the prediction of psychomotor speed in older persons with depression. Am J Psychiatry. 2002;159(12):2096-2098.
39. Tiemeier H, van Tuijl HR, Hofman A, Meijer J, Kiliaan AJ, Breteler MM. Vitamin $\mathrm{B}_{12}$, folate, and homocysteine in depression: the Rotterdam Study. Am J Psychiatry. 2002;159(12):2099-2101.

40. Nabi H, Bochud M, Glaus J, et al. Association of serum homocysteine with major depressive disorder: results from a large population-based study. Psychoneuroendocrinology. 2013;38(10):2309-2318.

41. Alexopoulos GS, Meyers BS, Young RC, Campbell S, Silbersweig D, Charlson M. "Vascular depression" hypothesis. Arch Gen Psychiatry. 1997;54(10):915-922.

42. Karabag T, Kaya A, Temizhan A, Koc F, Yavuz S, Cam S. The influence of homocysteine levels on endothelial function and their relation with microvascular complications in T2DM patients without macrovascular disease. Acta Diabetol. 2007;44(2):69-75.

43. Blasko I, Grubeck-Loebenstein B. Role of the immune system in the pathogenesis, prevention, and treatment of Alzheimer's disease. Drugs Aging. 2003;20(2):101-113.

44. Ozbek Z, Kucukali CI, Ozkok E, et al. Effect of the methylenetetrahydrofolate reductase gene polymorphisms on homocysteine, folate, and vitamin $\mathrm{B}_{12}$ in patients with bipolar disorder and relatives. Prog Neuropsychopharmacol Biol Psychiatry. 2008;32(5):1331-1337.

45. Dittmann S, Seemuller F, Grunze HC, et al. The impact of homocysteine levels on cognition in euthymic bipolar patients: a cross-sectional study. J Clin Psychiatry. 2008;69(6):899-906.

46. Dittmann S, Seemuller F, Schwarz MJ, et al. Association of cognitive deficits with elevated homocysteine levels in euthymic bipolar patients and its impact on psychosocial functioning: preliminary results. Bipolar Disord. 2007;9(1-2):63-70.

47. Seshadri S, Beiser A, Selhub J, et al. Plasma homocysteine as a risk factor for dementia and Alzheimer's disease. N Engl J Med. 2002; 346(7): 476-483.

48. Seshadri S, Wolf PA, Beiser AS, et al. Association of plasma total homocysteine levels with clinical brain injury: cerebral volumes, white matter hyperintensity, and silent brain infarcts at volumetric magnetic resonance imaging in the Framingham Offspring Study. Arch Neurol. 2008;65(5):642-649.

49. Lanctot KL, Herrmann N, Black SE, et al. Apathy associated with Alzheimer's disease: use of dextroamphetamine challenge. Am J Geriatr Psychiatry. 2008;16(7):551-557.

50. Spiro HR, Schimke RN, Welch JP. Schizophrenia in a patient with a defect in methionine metabolism. J Nerv Ment Dis. 1965;141(3):285-290.

51. Pollin W, Cardon PV Jr, Kety SS. Effects of amino acid feedings in schizophrenic patients treated with iproniazid. Science. 1961; 133(3446):104-105.

52. Regland B, Johansson BV, Grenfeldt B, Hjelmgren LT, Medhus M. Homocysteinemia is a common feature of schizophrenia. $J$ Neural Transm Gen Sect. 1995;100(2):165-169.

53. Levine J, Stahl Z, Sela BA, Gavendo S, Ruderman V, Belmaker RH. Elevated homocysteine levels in young male patients with schizophrenia. Am J Psychiatry. 2002;159(10):1790-1792.

54. Virgos C, Martorell L, Simo JM, et al. Plasma homocysteine and the methylenetetrahydrofolate reductase C677T gene variant: lack of association with schizophrenia. Neuroreport. 1999;10(10):2035-2038.

55. Kim WK, Pae YS. Involvement of N-methyl-D-aspartate receptor and free radical in homocysteine-mediated toxicity on rat cerebellar granule cells in culture. Neurosci Lett. 1996;216(2):117-120.

56. Lipton SA, Kim WK, Choi YB, et al. Neurotoxicity associated with dual actions of homocysteine at the N-methyl-D-aspartate receptor. Proc Natl Acad Sci U S A. 1997;94(11):5923-5928. 


\section{Publish your work in this journal}

Neuropsychiatric Disease and Treatment is an international, peerreviewed journal of clinical therapeutics and pharmacology focusing on concise rapid reporting of clinical or pre-clinical studies on a range of neuropsychiatric and neurological disorders. This journal is indexed on PubMed Central, the 'PsycINFO' database and CAS,

and is the official journal of The International Neuropsychiatric Association (INA). The manuscript management system is completely online and includes a very quick and fair peer-review system, which is all easy to use. Visit http://www.dovepress.com/testimonials.php to read real quotes from published authors.

Submit your manuscript here: http://www.dovepress.com/neuropsychiatric-disease-and-treatment-journal 